\title{
Effect of Magnetic Field on Entropy Generation in a Microchannel Heat Sink with Offset Fan Shaped
}

\author{
Mohammad Nasiri ${ }^{1}$, Mohammad Mehdi Rashidi ${ }^{2,3, *}$ and Giulio Lorenzini ${ }^{4}$ \\ Received: 3 November 2015; Accepted: 23 November 2015; Published: 29 December 2015 \\ Academic Editor: Kevin H. Knuth \\ 1 Department Mechanical Engineering, Faculty of Mechanical Engineering, University of Tabriz, \\ Tabriz 5166616471, Iran; m.nasiri1989@gmail.com \\ 2 Shanghai Key Lab of Vehicle Aerodynamics and Vehicle Thermal Management Systems, Tongji University, \\ Shanghai 201804, China \\ 3 ENN-Tongji Clean Energy Institute of Advanced Studies, Tongji University, Shanghai 201804, China \\ 4 Department of Industrial Engineering, University of Parma, Parma 43124, Italy; giulio.lorenzini@unipr.it \\ * Correspondence: mm_rashidi@tongji.com or mm_rashidi@yahoo.com; Tel.: +86-21-6958-3934
}

\begin{abstract}
In this study, convection flow in microchannel heat sink with offset fan-shaped reentrant cavities in sidewall filled with $\mathrm{Fe}_{3} \mathrm{O}_{4}$-water is numerically investigated. The effects of changing some parameters such as Reynolds number and magnetic field are considered. The nanofluid flow is laminar, steady and incompressible, while the thermo-physical properties of nanoparticles were assumed constant. A finite volume method and two phase mixture models were used to simulate the flow. The obtained results show that the frictional entropy generation increases as Reynolds number increases, while a reverse trend is observed for thermal entropy generation. By applying a non-uniform magnetic field, the entropy generation due to heat transfer decreases at first and then increases. When using the uniform magnetic field, the frictional entropy generation and thermal entropy generation is negligible. For all studied cases, the total entropy generation decreases using non-uniform magnetic fields. The results indicate that by increasing the magnetic field power, the total entropy generation decreases.
\end{abstract}

Keywords: nanofluid; microchannel heat sink; magnetic field; entropy generation

\section{Introduction}

With the development of science and technology, the decreasing size of the systems has many advantages in comparison with conventional size, including optimized size, accessiblity, and enhance functionality. Microchannels are the basic structures in these systems. In recent years, microchannels have become very important is some industries and engineering applications such as heat pumps, heat exchangers, medical and aerospace devices. The optimal design of microchannels depends considerably on their thermal efficiency. Tuckerman and Pease [1] studied hydrothermal behavior in microchannels for the frist time.

The heat transfer of flowing fluids is limited according to the thermal properties of fluids. The thermal conductivity of base fluids, such as air or water, is low. However, to increase the heat transfer in a microchannel one needs to improve thermal properties of base fluids. Choi [2] studied dilute liquid-particle mixtures, called nanofluids, indicating that thermal conductivity values are $20 \%-150 \%$ higher than those of base fluids.

Many studies analyzed the convective heat transfer characteristics of nanofluids in microchannel heat sink [3-7]. Li and Kleinstreuer [8] numerically studied CuO-water nanofluid flow in a trapezoidal microchannel. They optimized nanoparticles concentration for minimizing entropy generation. 
Mital [9] numerically investigated heat transfer nanofluid in microchannel heat sink with developed laminar flow. He optimized the design of microchannel heat sinks with nanofluid flow.

Magnetic fluid (ferrofluid) is a stable colloidal suspension of sub-domain magnetic particles that are coated with a surfactant layer in a liquid carrier. The advantage of the use of ferrofluids is that both fluid flow and heat transfer can be controlled by external magnetic fields [10]. Aminfar et al. [11,12] numerically studied the effects uniform and non-uniform magnetic field on hydrothermal behaviors in a vertical pipe and square duct with using two-phase mixture model. Their result indicated that the positive gradient axial field decreases the Nusselt number and the friction factor; but the negative gradient axial field and uniform transverse field enhance these numbers.

A powerful tool for studing the revesibility is the analysis of entropy generation. Yang et al. [13] showed that the frictional entropy generation increases by increasing buoyancy effect while the Reynolds number is constant but thermal entropy generation is not sensitive to buoyancy forces. Yilbas et al. [14] investigated the natural convection efficiency and the entropy generation in a square cavity with different temperatures for upper and lower walls. Also, Erbay et al. [15] and Magherbi et al. [16] studied transient entropy generation in a square whose right wall was completely cooled and whose left sidewalls were completely or partially heated.

Jery et al. [17] studied the effects of magnetic field, Prandtl, and Grashof number on entropy generation in natural convection. They founded that the magnetic field decreases the convection currents, the heat transfer and entropy generation inside the enclosure. Yazdi et al. [18,19] investigated the entropy generation numbers, as well as the Bejan number in Mgneto Hydro Dinamics (MHD) fluid flow in open parallel microchannels. They showed that entropy generation reduces in the presence of magnetic field.

Many studies have been done for entropy generation analysis by various boundary conditions [17-19]. Nevertheless, to the best of our knowledge, there has not yet been any investigation made into the effects of uniform and non-uniform transverse magnetic fields on entropy generation on ferrofluid in a microchannel. In this work, the entropy generation of nanofluids flow in a microchannel heat sink is investigated using a mixture model. The affects of uniform and non-uniform transverse magnetic fields and of Reynolds number variation on entropy generation have studied. Therefore, the main goal of this study is reducing entropy generation losses by varying applied magnetic field. Some new investigations about analytical and numerical simulations of nanofluids can be found in [20-26].

\section{Governing Equations}

Researchers use different methods for numerical analysis in multi-phase flows. The mixture model is generally accurate for nanofluid analyses $[27,28]$. In this study, the flow was assumed to be laminar, steady and incompressible with constant thermo-physical properties. The effects of dissipation and body forces are negligible. Also, the Boussinesq approximation was used to calculate the density variations due to buoyancy force. Considering these assumptions, the dimensional equations are as follows:

Continuity equations:

$$
\nabla\left(\rho_{\mathrm{eff}} V_{\mathrm{m}}\right)=0
$$

Momentum equations:

$$
\begin{gathered}
\nabla\left(\rho_{\mathrm{eff}} \mathrm{V}_{\mathrm{m}} \mathrm{V}_{\mathrm{m}}\right) \quad=-\nabla \mathrm{P}+\nabla\left(\mu_{\mathrm{eff}} \nabla V_{\mathrm{m}}\right)+\rho_{\mathrm{eff}} \beta_{\mathrm{eff}} g\left(T-T_{\mathrm{C}}\right) \\
+\nabla\left(\sum_{k=1}^{n} \varphi_{\mathrm{k}} \rho_{\mathrm{k}} V_{\mathrm{dr}, \mathrm{k}} V_{\mathrm{dr}, \mathrm{k}}\right)+\mu_{0}(M . \nabla) H+\vec{J} \times \vec{B}
\end{gathered}
$$

The term (M. $\nabla) \mathrm{H}$ is called Kelvin force; it results from the electric current flowing through the wire. In this equation, $M$ is the magnetization, determined as [29]:

$$
M=\chi H
$$


where $\chi$ is magnetic susceptibility of ferrofluid equal to 0.03873 . This value was calculated at $4 \%$ volume assuming a mean diameter of $30 \mathrm{~nm} . \mathrm{H}$ is the magnetic field vector and is defined as [30]

$$
H(x . y)=\frac{I}{2 \pi} \frac{1}{\sqrt{(x-a)^{2}+(y-b)^{2}}}
$$

where

$$
\begin{aligned}
H_{x}(x \cdot y) & =\frac{I}{2 \pi} \frac{(x-a)}{(x-a)^{2}+(y-b)^{2}} \\
H_{y}(x . y) & =-\frac{I}{2 \pi} \frac{(y-b)}{(x-a)^{2}+(y-b)^{2}}
\end{aligned}
$$

I is electric intensity. The wire direction is parallel to the longitudinal channel and in the center of cross section at the $(a, b)$.

In Equation (2), $\vec{J} \times \vec{B}$ refers to the Lorentz force determined as:

$$
J=\sigma_{e f f}(\vec{V} \times \vec{B})
$$

where $\vec{B}$ is the induced magnetic field; the applied magnetic field can be assumed as uniform. The induced magnetic field can be calculated by intensity of magnetic field:

$$
\vec{B}=\mu_{0} \times H
$$

Energy equation:

$$
\nabla\left[\sum_{k=1}^{n}\left(\rho C_{\mathrm{p}}\right)_{\mathrm{k}} \varphi_{\mathrm{k}} V_{\mathrm{k}} T\right]=\nabla\left(k_{\mathrm{eff}} \nabla T\right)+\frac{1}{\sigma_{e f f}}(\vec{J} \times \vec{J})
$$

Volume fraction equations:

$$
\nabla\left(\varphi_{\mathrm{p}} \rho_{\mathrm{p}} V_{\mathrm{m}}\right)=-\nabla\left(\varphi_{\mathrm{p}} \rho_{\mathrm{p}} V_{\mathrm{dr}, \mathrm{p}}\right)
$$

In Equation (10), $V_{m}$, and $V_{d r}$ are the mean velocity and the drift velocity, respectively, which can be calculated as:

$$
\begin{gathered}
V_{\mathrm{m}}=\frac{\sum_{\mathrm{k}=1}^{\mathrm{n}} \varphi_{\mathrm{k}} \rho_{\mathrm{k}} V_{\mathrm{k}}}{\rho_{\mathrm{eff}}} \\
V_{\mathrm{dr}, \mathrm{k}}=V_{\mathrm{k}}-V_{\mathrm{m}}
\end{gathered}
$$

where $\varphi$ is the volume fraction of nanoparticles. The slip velocity defined as the velocity of base fluid (bf) with respect to velocity of nanoparticles ( $p$ ) and determined as:

$$
V_{\mathrm{pf}}=V_{\mathrm{p}}-V_{\mathrm{bf}}
$$

The drift velocity depends on the slip velocity:

$$
V_{\mathrm{dr}, \mathrm{p}}=V_{\mathrm{pf}}-\sum_{\mathrm{k}=1}^{\mathrm{n}} \frac{\varphi_{\mathrm{k}} \rho_{\mathrm{k}}}{\rho_{\mathrm{eff}}} V_{\mathrm{fk}}
$$

The slip velocity is presented by Manninen et al. [31]:

$$
V_{\mathrm{bf}}=\frac{\rho_{\mathrm{p}} d_{\mathrm{p}}^{2}}{18 \mu_{\mathrm{bf}} f_{\mathrm{drag}}} \frac{\left(\rho_{\mathrm{p}}-\rho_{\mathrm{eff}}\right)}{\rho_{\mathrm{p}}} r
$$


where $f_{\text {drag }}$ is the drag coefficient that can be defined as follows:

$$
f_{\text {drag }}=\left\{\begin{array}{c}
1+0.15 \operatorname{Re}_{\mathrm{p}}^{0.687} \operatorname{Re}_{\mathrm{p}} \leqslant 1000 \\
0.0183 \operatorname{Re}_{\mathrm{p}} \operatorname{Re}_{\mathrm{p}}>1000
\end{array}\right.
$$

In Equation (16), $\operatorname{Re}_{\mathrm{p}}=\mathrm{V}_{\mathrm{m}} \mathrm{d}_{\mathrm{p}} / \mathrm{v}_{\text {eff }}$ is the Reynolds number of particles. The acceleration $r$ is calculated by:

$$
r=g-\left(V_{\mathrm{m}} \nabla\right) V_{\mathrm{m}}
$$

\section{Nanofluids Properties}

The physical properties of water and $\mathrm{Fe}_{3} \mathrm{O}_{4}$ nano-particles with mean diameters $(30 \mathrm{~nm})$ are shown in Table 1. The water- $\mathrm{Fe}_{3} \mathrm{O}_{4}$ nanofluidis homogenous and the thermos-physical mixture properties calculated for the ferrofluid with $4 \%$ volume fraction of nanoparticles.

Table 1. Properties of base fluid and nanoparticles [12,32].

\begin{tabular}{ccc}
\hline Properties & Water & $\mathrm{Fe}_{3} \mathrm{O}_{4}$ \\
\hline Density $\left(\mathrm{kg} / \mathrm{m}^{3}\right)$ & 997.1 & 5200 \\
Specific heat capacity $(\mathrm{J} / \mathrm{kg} \cdot \mathrm{K})$ & 4180 & 670 \\
Thermal conductivity $(\mathrm{W} / \mathrm{m} \cdot \mathrm{K})$ & 0.613 & 6 \\
Electrical conductivity $(\mathrm{s} / \mathrm{m})$ & 5.3 & 25,000 \\
Dynamic viscosity $(\mathrm{kg} / \mathrm{m} \cdot \mathrm{s})$ & 0.0009963 & - \\
\hline
\end{tabular}

The physical properties are calculated by means of the following equations:

Density of nanofluid:

$$
\rho_{e f f}=(1-\varphi) \rho_{b f}+\varphi \rho_{p}
$$

Specific heat capacity of the nanofluid:

$$
\left(\rho_{e f f} C_{p_{e f f}}\right)=(1-\varphi)\left(\rho C_{p}\right)_{b f}+\varphi\left(\rho C_{p}\right)_{p}
$$

Dynamic viscosity of nanofluid [33]:

$$
\mu_{e f f}=\mu_{b f}\left(1+2.5 \varphi+4.375 \varphi^{2}\right)
$$

Thermal expansion coefficient of nanofluid [29]:

$$
\beta_{\text {eff }}=\left[\frac{1}{1+\frac{(1-\varphi) \rho_{b f}}{\varphi \rho_{p}}} \frac{\beta_{p}}{\beta_{b f}}+\frac{1}{1+\frac{\varphi \rho_{p}}{(1-\varphi) \rho_{b f}}}\right] \beta_{b f}
$$

Electrical conductivity [12]:

$$
\sigma_{e f f}=(1-\varphi) \sigma_{b f}+\varphi \sigma_{p}
$$

Thermal conductivity of nanofluid [34]:

$$
\frac{k_{\text {eff }}}{k_{\mathrm{bf}}}=1+64.7 \varphi^{0.746}\left(\frac{d_{\mathrm{bf}}}{d_{\mathrm{p}}}\right)^{0.369}\left(\frac{k_{\mathrm{p}}}{k_{\mathrm{bf}}}\right)^{0.7476} \operatorname{Pr}_{\mathrm{bf}}^{0.9955} \operatorname{Re}_{\mathrm{bf}}^{1.2321}
$$

$d_{b f}$ and $d p$ are molecular base fluid $(0.2 \mathrm{~nm})$ and particle $(30 \mathrm{~nm})$ diameter. 
In Equation (23) Pr and Re are Prandtl and Reynolds number, respectively defined as:

$$
\begin{gathered}
\operatorname{Pr}_{\mathrm{bf}}=\frac{\eta}{\rho_{\mathrm{bf}} \alpha_{\mathrm{bf}}} \\
\operatorname{Re}_{\mathrm{bf}}=\frac{\rho k_{\mathrm{B}} T}{3 \pi \eta^{2} \lambda_{\mathrm{bf}}}
\end{gathered}
$$

In Equation (21):

$$
\eta=\mathrm{A} \times 10^{\frac{\mathrm{B}}{T-\mathrm{C}}}, \mathrm{A}=2.414 \times 10^{-5}, \mathrm{~B}=247, \mathrm{C}=140
$$

Also, in Equation (25) $\lambda_{b f}$ is water mean free path $(17 \mathrm{~nm})$ and $k_{B}$ is Boltzmann constant $\left(1.3807 \times 10^{-23} \mathrm{~J} / \mathrm{K}\right)$.

\section{Definition of Physical Domain}

The schematic diagram of the microchannel heat sink with offset fan-shaped reentrant cavities in sidewall is presented in Figure 1. The channel length is $2.70 \mathrm{~mm}$ and channel width is $300 \mu \mathrm{m}$, with a thickness of $350 \mu \mathrm{m}$. The constant cross section zone of the investigated heat sink has a constant width of $100 \mu \mathrm{m}$ and constant depth of $200 \mu \mathrm{m}$. The pitch distance of two longitudinal microchannels is $150 \mu \mathrm{m}$. The space between a pair cavity is $300 \mu \mathrm{m}$. The field radius of the fan-shaped reentrant cavity is $100 \mu \mathrm{m}$.

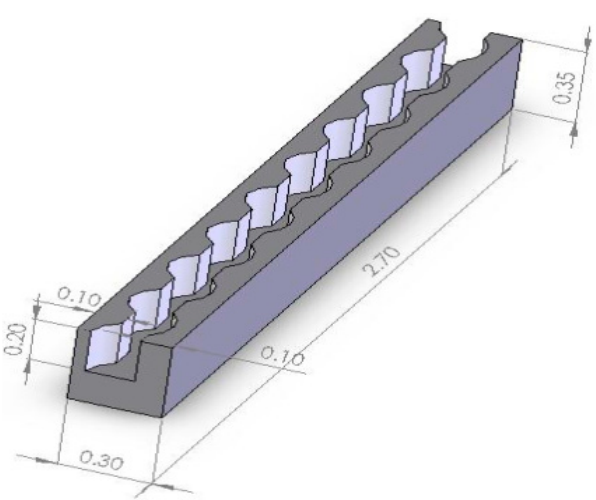

(a)

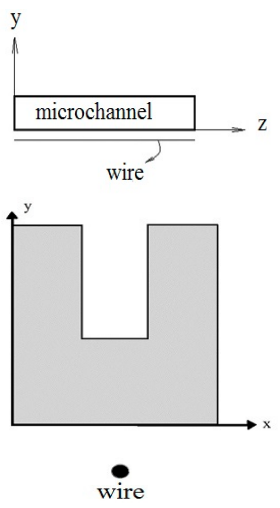

(b)

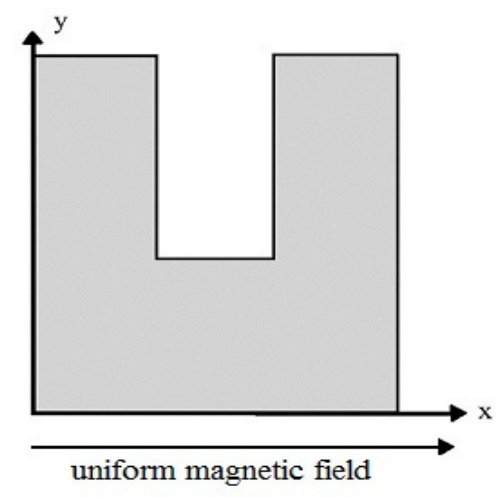

(c)

Figure 1. Shematic of microchannel and magnetic field (a) Geometry of microchannel in the present study; (b) Cross-sectional plane of transverse non-uniform magnetic field; (c) Transverse uniform magnetic field.

The governing equations are solved by applying the boundary conditions in the entrance of microchannel $(Z=0)$,

$$
\mathrm{u}=0 ; \mathrm{v}=0 ; \mathrm{w}=\mathrm{v}_{0} ; \mathrm{T}=\mathrm{T}_{0}
$$

at the microchannel outlet $(Z=2.7 \mathrm{~mm})$ :

$$
-\mathrm{K}_{\mathrm{w}} \frac{\partial \mathrm{T}_{\mathrm{w}}}{\partial \mathrm{z}}=0 ; \mathrm{u}=0 ; \mathrm{v}=0 ; \mathrm{P}=\mathrm{P}_{\mathrm{atm}}
$$

In the left and right sides of microchannel outer adiabatic walls $(X=0 \& w)$ :

$$
-\mathrm{K}_{\mathrm{w}} \frac{\partial \mathrm{T}_{\mathrm{w}}}{\partial \mathrm{x}}=0
$$


In the microchannel inner walls:

$$
\begin{aligned}
\left.\frac{\partial \mathrm{u}}{\partial \mathrm{n}}\right|_{\text {wall }}+\left.\frac{\partial \mathrm{v}}{\partial \mathrm{n}}\right|_{\text {wall }}=0, & -\mathrm{K}_{\mathrm{w}}\left(\frac{\partial \mathrm{T}_{\mathrm{w}}(\mathrm{x}, \mathrm{y}, \mathrm{z})}{\partial \mathrm{n}}\right)=-\mathrm{K}_{\mathrm{eff}}\left(\frac{\partial \mathrm{T}_{\text {eff }}(\mathrm{x}, \mathrm{y}, \mathrm{z})}{\partial \mathrm{n}}\right) \\
& -\mathrm{K}_{\mathrm{w}}\left(\frac{\partial \mathrm{T}_{\mathrm{w}}}{\partial \mathrm{y}}\right)=\mathrm{q}_{\mathrm{w}}
\end{aligned}
$$

Finally, a constant heat flux condition is imposed at micro heat sink bottom wall $(y=0)$.

\section{Numerical Method}

In this study, the non-linear partial differential equations are numerically solved by means of the finite volume (FV) method. The Semi-Implicit Method for Pressure Linked Equations-Consistent (SIMPLEC) algorithm is applied for coupling the velocity and pressure fields. The second order upwind scheme is selected for the discretization of momentum and energy equations. Also, the first order scheme is used for discretization of solid phase equations. The convergence of solutions is assumed as $\left|\left(\Phi^{\mathrm{n}+1}-\Phi^{\mathrm{n}}\right) / \Phi^{\mathrm{n}+1}\right| \leqslant 10^{-8}$.

In order to ensure that the results are independent of the computational grids, several grid sizes are investigated and the results for the constant heat flux at $\operatorname{Re}=300$ are given in Table 2. Because of a very small difference between the third case with fourth cases and to save computation time, 1188000 grids have been chosen, respectively.

In order to validate the numerical method used for the present simulation, the results in terms of mean temperature at the bottom of the microchannel (Figure 2) and entropy generation (Table 3) have been compared with the results provided by Chai et al. [35] and Balaji et al. [36].

Table 2. Grid independent test $\left(\operatorname{Re}=200, \mathrm{~T}_{0}=300,4 \%\right.$ vol. $)$.

\begin{tabular}{ccc}
\hline Grid & $\mathrm{T} / \mathrm{T}_{\mathbf{0}}$ & $\mathrm{V} / \mathrm{V}_{\mathbf{0}}$ \\
\hline 672914 & 1.027 & 1.038 \\
889440 & 1.019 & 1.029 \\
1188000 & 1.013 & 1.023 \\
1591128 & 1.011 & 1.02 \\
\hline
\end{tabular}

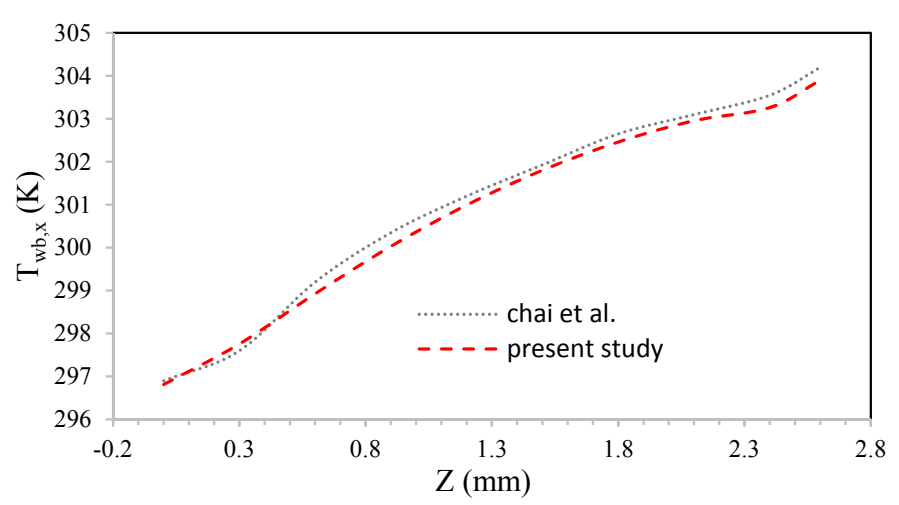

Figure 2. Comparison of the results for average temperature bottom heat sink.

Table 3. Validation of the present study.

\begin{tabular}{ccc}
\hline \multicolumn{3}{c}{ Total Entropy Generation Rate } \\
\hline $\mathrm{V}_{\text {in }}$ & Balaji et al. [36] & Present study \\
$2 \mathrm{~m} / \mathrm{s}$ & 0.0395 & 0.0412 \\
$4 \mathrm{~m} / \mathrm{s}$ & 0.0295 & 0.0324 \\
$6 \mathrm{~m} / \mathrm{s}$ & 0.0223 & 0.0242 \\
\hline
\end{tabular}


Boundary conditions applied to the fluid caused a non-equilibrium flow that leads to entropy generation in the flow field. In this study, the entropy generation is due to the irreversibility caused by the heat transfer and flow friction. The average entropy generation due to heat transfer, $\mathrm{s}_{\mathrm{f} \text {-ave, }}$ is defined as follows [37]:

$$
\mathrm{s}_{\mathrm{f}-\mathrm{ave}}=\frac{\mathrm{k}_{\mathrm{eff}}}{\overline{\mathrm{T}}^{2}}\left[\left(\frac{\partial \overline{\mathrm{T}}}{\partial \mathrm{x}}\right)^{2}+\left(\frac{\partial \overline{\mathrm{T}}}{\partial \mathrm{y}}\right)^{2}+\left(\frac{\partial \overline{\mathrm{T}}}{\partial \mathrm{z}}\right)^{2}\right]
$$

The average entropy generation due to viscous dissipation, $\mathrm{s}_{\mathrm{T}-\mathrm{ave}}$, is [37]:

$$
\mathrm{s}_{\mathrm{f}-\mathrm{ave}}=\frac{\mu_{\mathrm{eff}}}{\overline{\mathrm{T}}}\left\{2\left[\left(\frac{\partial \overline{\mathrm{u}}}{\partial \mathrm{x}}\right)^{2}+\left(\frac{\partial \overline{\mathrm{v}}}{\partial \mathrm{y}}\right)^{2}+\left(\frac{\partial \overline{\mathrm{w}}}{\partial \mathrm{z}}\right)^{2}\right]+\left(\frac{\partial \bar{u}}{\partial y}+\frac{\partial \bar{v}}{\partial x}\right)^{2}+\left(\frac{\partial \bar{u}}{\partial z}+\frac{\partial \bar{w}}{\partial x}\right)^{2}+\left(\frac{\partial \bar{w}}{\partial w}+\frac{\partial \bar{v}}{\partial z}\right)^{2}\right\}
$$

The average entropy generation due to magnetic field can be expressed as follows [37]:

$$
\mathrm{s}_{\text {mag-ave }}=\frac{\sigma_{\text {eff }} \vec{B}^{2} \vec{w}^{2}}{\overline{\mathrm{T}}}
$$

The total entropy generation is then given by:

$$
\mathrm{s}_{\text {tot }}=\mathrm{s}_{\mathrm{f}-\mathrm{ave}}+\mathrm{s}_{\mathrm{T}-\mathrm{ave}}+\mathrm{s}_{\mathrm{mag}}
$$

where $\overline{\mathrm{T}}$ is the average bulk temperature of the fluid flow.

\section{Result and Discussion}

The variations of entropy generations and Reynolds number for various transverse magnetic fields are shown in Figure 3. It can be seen that for a given fluid, the frictional entropy generation increases by increasing the Reynolds number (Figure 3a). Applying a transverse uniform and non-uniform magnetic field to the ferrofluid did not affect entropy generation due to friction.

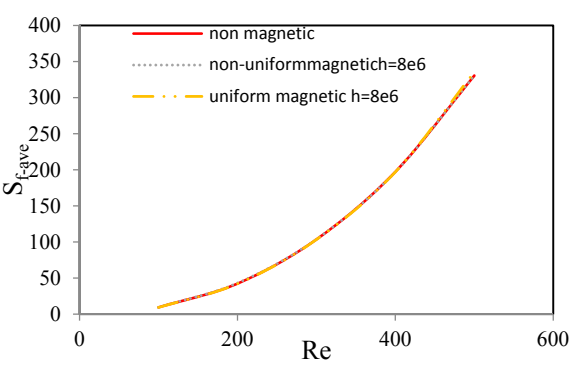

(a)

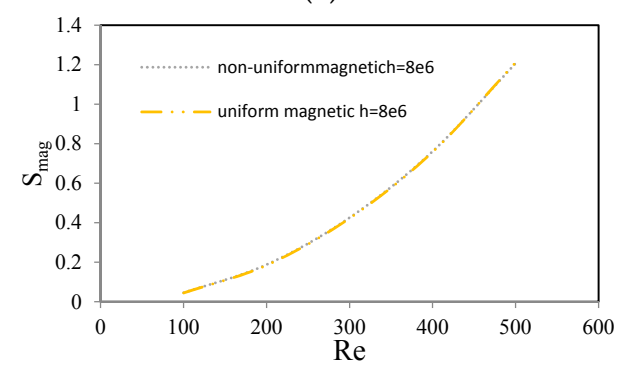

(c)

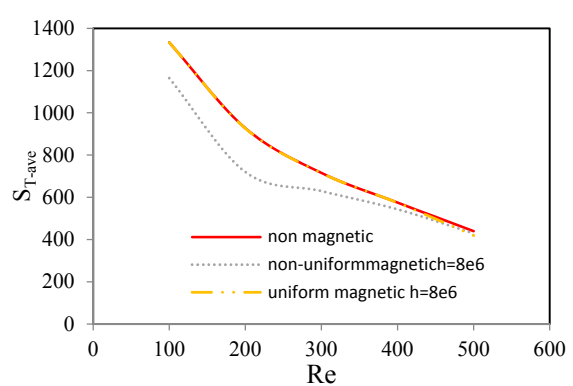

(b)

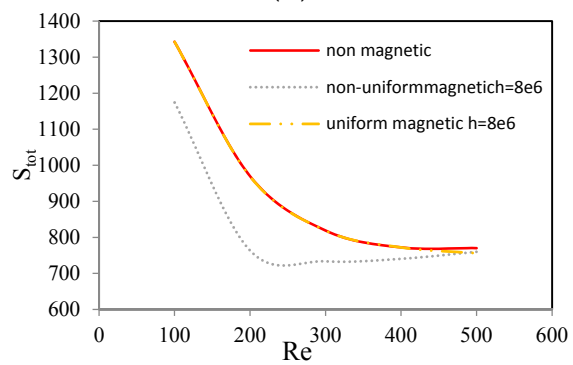

(d)

Figure 3. Effect magnetic field on nanofluid for various Reynolds number; (a) Frictional entropy generation by dissipation; (b) Entropy generation due to thermal irreversibility; (c) Entropy generation due to applied magnetic field; (d) Total entropy generation. 
The variations of thermal entropy generations vs. Reynolds number for various transverse magnetic field is presented in Figure 3b. The entropy generation due to heat transfer decreases by increasing the Reynolds number; high Reynolds number causes better heat transfer performance as well as higher temperature gradient. The non-uniform transverse magnetic field resonance vortex enhances heat transfer and reduces the entropy generation due to thermal effects, but increasing Reynolds number and viscosity effect on ferrofluid flow decreases the effect of magnetic field. The application of a uniform magnetic field did not affect any thermal entropy generation.

The variations magnetic entropy generation and Reynolds number is presented in Figure 3c. The effect of magnetic entropy generation is very small and can be neglected comparing with frictional and thermal entropy generation [19].

The total entropy generation decreases as Reynolds number increases (Figure 3d). When a uniform transverse magnetic field is applied, the entropy generation reduces to a negligible amount. In contrast, when applying a non-uniform magnetic field, the total entropy generation firstly decreases and then increases.

Figure 4 shows the variations of entropy generation versus the transverse magnetic field power for same condition and $\operatorname{Re}=300$. By strengthening the uniform transverse magnetic field, the entropy generation due to friction and thermal entropy generation reduces to small amounts (Figure $4 a, b)$. The low intensity magnetic field cannot overcome viscous force; therefore, the magnetic field cannot affect average velocity. A stronger non-uniform transverse magnetic field causes an increase in vortex power and heat transfer, while the frictional entropy generation increases and the thermal entropy generation decreases too much. By increasing the intensity of the uniform magnetic field, the vortex becomes weak and flow will be inclined to bottom microchannel heat sink; therefore, the thermal and frictional entropy generation decreases at maximum intensity field.

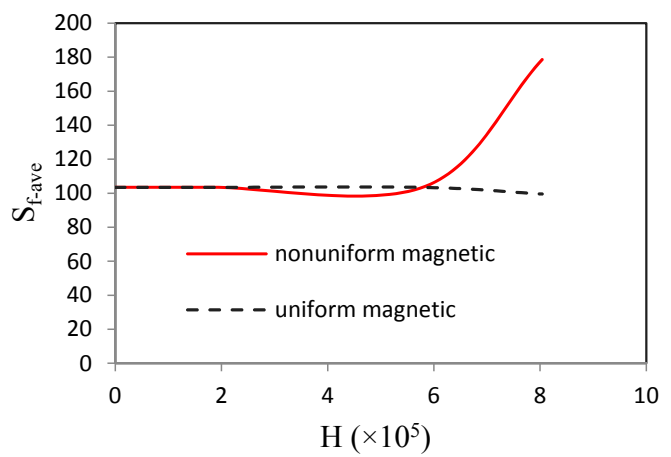

(a)

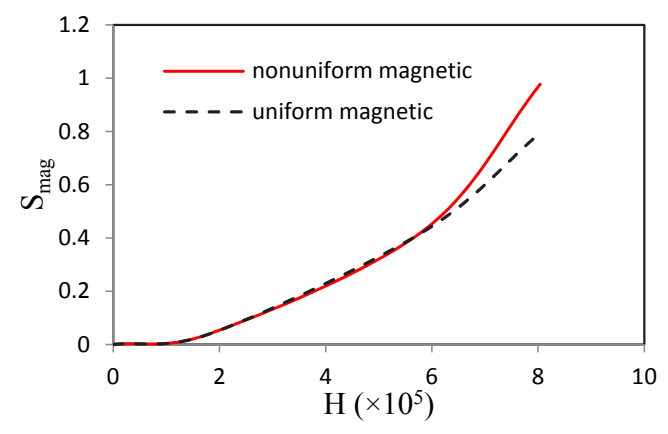

(c)

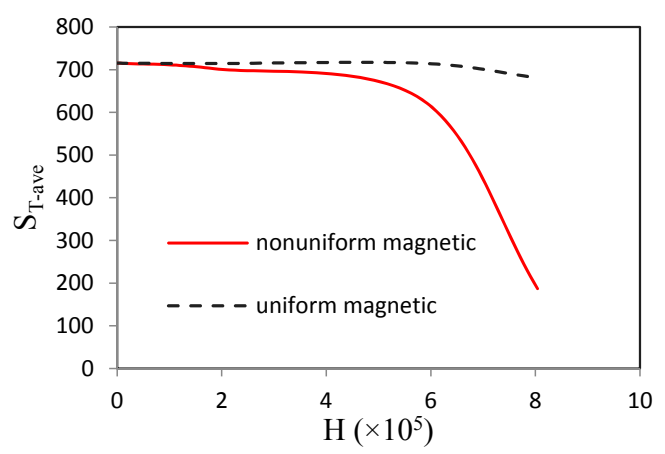

(b)

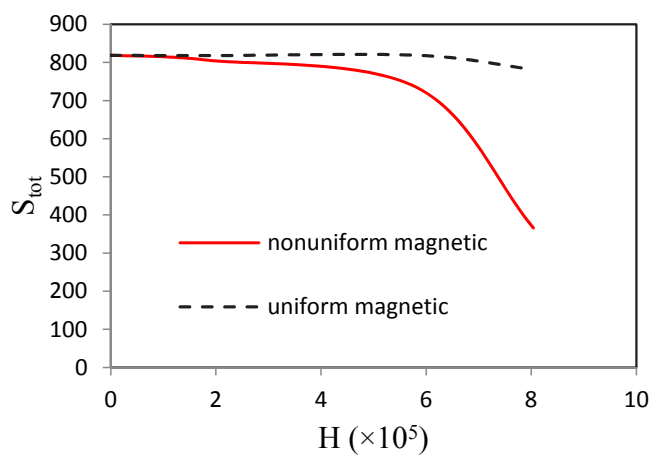

(d)

Figure 4. Effect magnetic field on nanofluid for constant Reynolds number $(\operatorname{Re}=300)$ (a) Frictional entropy generation by dissipation; (b) Entropy generation due to thermal irreversibility; (c) Entropy generation due to applied magnetic field; (d) Total entropy generation with various magnetic field power for $\operatorname{Re}=300$. 
The variations of magnetic entropy generations and various intensity transverse magnetic fields are shown in Figure 3. The magnetic entropy generation increases with increasing intensity magnetic field. The amount of non-uniform magnetic entropy is more than uniform magnetic entropy in the maximum intensity magnetic field because the mean velocity flow is more than the mean velocity in the applied uniform magnetic field.

The variation of the total entropy generation is shown in Figure 4c. As observed, the total entropy generation increases as Reynolds number increases, indicating that the thermal entropy generation is dominant.

\section{Conclusions}

In this study, the laminar ferrofluid flow in a microchannel heat sink subject to transverse magnetic field is numerically investigated. The influences of Reynolds number and magnetic power on entropy generations are studied. The results show that the average frictional entropy generation increases as Reynolds number increases. Also, the average thermal entropy generation decreases by increasing the Reynolds number. Transverse uniform and non-uniform magnetic fields did not affect the frictional entropy generation. In addition, the results showed that increase of the magnetic field power causes a decrease of the total entropy generation.

Acknowledgments: Giulio Lorenzini is the Guest editor of the special issue, and page charge will waive for this reason.

Author Contributions: Mohammad Nasiri and Mohammad Mehdi Rashidi conceived and designed the numerical simulation; Giulio Lorenzini proposed the governing equations and did physical description for the physical results. Mohammad Nasiri, Mohammad Mehdi Rashidi and Giulio Lorenzini have read and approved the final manuscript.

Conflicts of Interest: The authors declare no conflict of interest.

\section{Abbreviations}

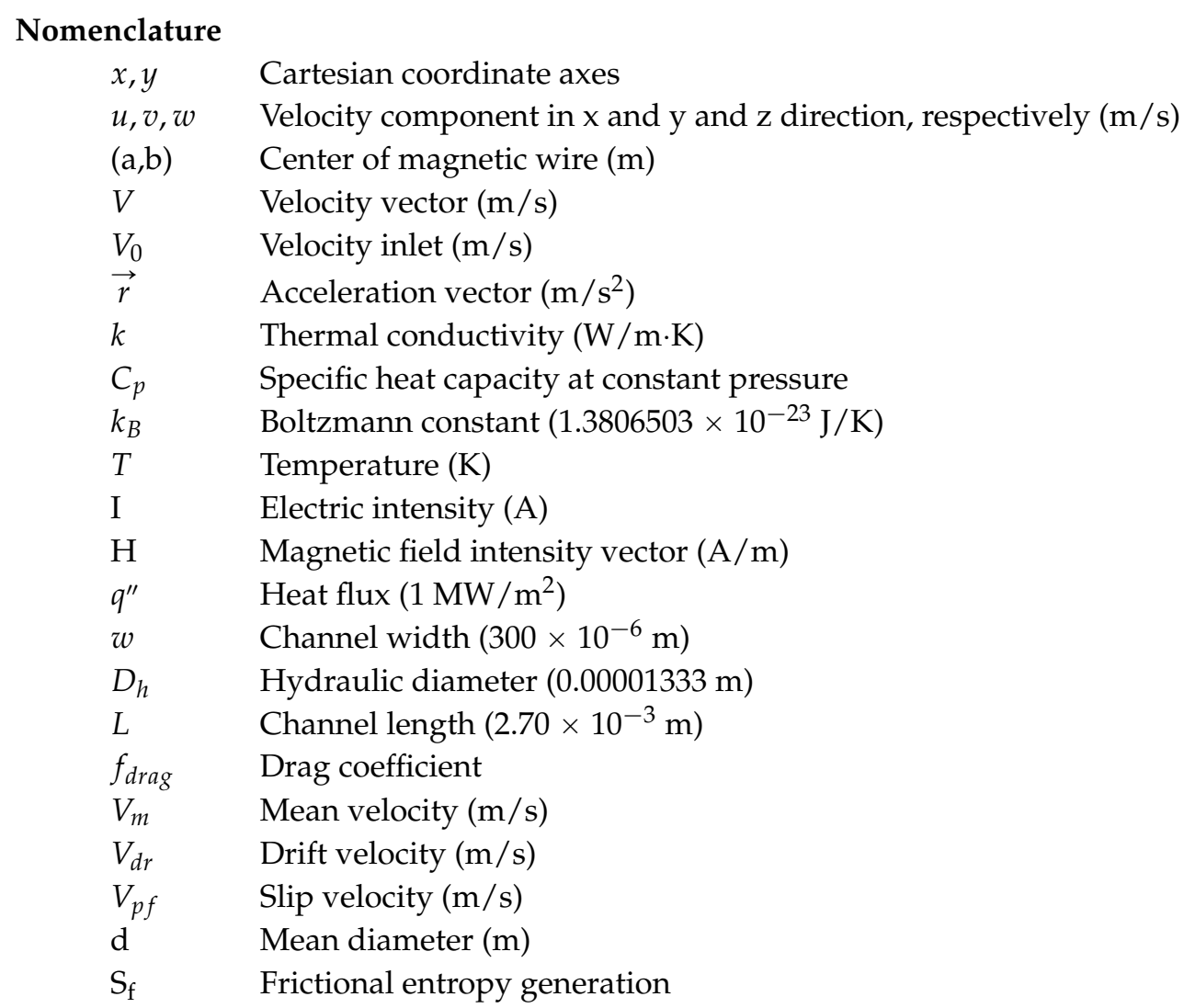




$\begin{array}{ll}\mathrm{S}_{\mathrm{T}} & \text { Thermal entropy generation } \\ \mathrm{S}_{\mathrm{mag}} & \text { Magnetic entropy generation } \\ \operatorname{Re} & \text { Reynolds number } \\ \mathrm{Pr} & \text { Prandtlnumber } \\ \vec{B} & \text { Magnetic field }(\mathrm{T})\end{array}$

Greek symbols

$\begin{array}{ll}\mu_{0} & \text { magnetic permeability in vacuum }\left(4 \pi \times 10^{-7} \mathrm{Tm} / \mathrm{A}\right) \\ \mu & \text { Dynamic viscosity }(\mathrm{kg} / \mathrm{m} \cdot \mathrm{s}) \\ \beta & \text { Thermal expansion coefficient }\left(\text { thermal expansion coefficient }\left(\mathrm{K}^{-1}\right)\right. \\ \rho & \text { Density }\left(\mathrm{kg} / \mathrm{m}^{3}\right) \\ \lambda & \text { Mean free path }\left(17 \times 10^{-9} \mathrm{~m}\right) \\ \chi & \text { Magnetic susceptibility } \\ \varphi & \text { Particle volume fraction } \\ \sigma & \text { Electrical conductivity }(\mathrm{s} / \mathrm{m}) \\ c \text { cipts } & \\ p & \text { Particle } \\ b f & \text { Base fluid } \\ \text { eff } & \text { Effective } \\ \text { ave } & \text { Average }\end{array}$

\section{References}

1. Tuckerman, D.B.; Pease, R.F.W. High-Performance Heat Sinking for VLSI. IEEE Electron Device Lett. 1981, 2, 126-129. [CrossRef]

2. Choi, S.U.S.; Esterman, J.A. Enhancing thermal conductivity of fluids with nanoparticles. Am. Soc. Mech. Eng. 1995, 231, 99-106.

3. Aminossadati, S.M.; Raisi, A.; Ghasemi, B. Effects of magnetic field on nanofluid forced convection in a partially heated microchannel. Int. J. Non-Linear Mech. 2011, 46, 1373-1382. [CrossRef]

4. Yang, Y.T.; Lai, F.H. Lattice Boltzmann simulation of heat transfer and fluid flow in a microchannel with nanofluids. Heat Mass Transf. 2011, 47, 1229-1240. [CrossRef]

5. Lelea, $\mathrm{D}$. The performance evaluation of $\mathrm{Al}_{2} \mathrm{O}_{3}$ /water nanofluid flow and heat transfer in microchannel heat sink. Int. J. Heat Mass Transf. 2011, 54, 3891-3899. [CrossRef]

6. Mohammed, H.A.; Gunnasegaran, P.; Shuaib, N.H. The impact of various nanofluid types on triangular microchannels heat sink cooling performance. Int. Commun. Heat Mass Transf. 2011, 38, 767-773. [CrossRef]

7. Lelea, D.; Nisulescu, C. The micro-tube heat transfer and fluid flow of water based $\mathrm{Al}_{2} \mathrm{O}_{3}$ nanofluid with viscous dissipation. Int. Commun. Heat Mass Transf. 2011, 38, 704-710. [CrossRef]

8. Li, J.; Kleinstreuer, C. Entropy generation analysis for nanofluid flow in microchannels. J. Heat Transf. 2010, 132. [CrossRef]

9. Mital, M. Analytical analysis of heat transfer and pumping power of laminar nanofluid developing flow in microchannels. Appl. Therm. Eng. 2013, 50, 429-436. [CrossRef]

10. Nakatsuka, K.; Jeyadevan, B.; Neveu, S.; Koganezawa, H. The Magnetic Fluid for Heat Transfer Applications. J. Magn. Magn. Mater. 2002, 252, 360-362. [CrossRef]

11. Aminfar, H.; Mohammadpourfard, M.; Narrimanikahnamouei, Y. A 3D numerical-simulation of mixed convection of a magnetic nanofluid in the presence of non-uniformmagnetic field in a vertical tube using two phase mixture model. J. Magn. Magn. Mater. 2011, 323, 1963-1972. [CrossRef]

12. Aminfar, H.; Mohammadpourfard, M.; Mohseni, F. Two-phase mixture model simulation of the hydro-thermal behavior of an electrical conductive ferrofluid in the presence of magnetic fields. J. Magn Magn. Mater. 2012, 324, 830-842. [CrossRef]

13. Yang, G.; Wu, J.Y.; Yan, L. Flow reversal and entropy generation due to buoyancy assisted mixed convection in the entrance region of a three dimensional vertical rectangular duct. Int. J. Heat Mass Transf. 2013, 67, 741-751. [CrossRef] 
14. Yilbas, B.S.; Shuja, S.Z.; Gbadebo, S.A.; Al-Hamayle, H.I.A.; Boran, K. Naturalconvection and entropy generation in a square cavity. Int. J. Energy Res. 1998, 22, 1275-1290. [CrossRef]

15. Erbay, L.B.; Altac, Z.; Sulus, B. An analysis of the entropy generation in a square enclosure. Entropy 2003, 5, 496-505. [CrossRef]

16. Magherbi, M.; Abbassi, H.; Brahim, A.B. Entropy generation at the onset ofnatural convection. Int. J. Heat Mass Transf. 2003, 46, 3441-3450. [CrossRef]

17. Jery, A.E.; Hidouri, N.; Magherbi, M.; Brahim, A.B. Effect of an External Oriented Magnetic Field on Entropy Generation in Natural Convection. Entropy 2010, 12, 1391-1417. [CrossRef]

18. Yazdi, M.H.; Abdullah, S.; Hashim, I.; Sopian, K. Reducing Entropy Generation in MHD Fluid Flow over Open Parallel Microchannels Embedded in a Micropatterned Permeable Surface. Entropy 2013, 15, 4822-4843. [CrossRef]

19. Yazdi, M.H.; Abdullah, S.; Hashim, I.; Sopian, K. Entropy Generation Analysis of Open Parallel Microchannels Embedded Within a Permeable Continuous Moving Surface: Application to Magnetohydrodynamics (MHD). Entropy 2012, 14, 1-23. [CrossRef]

20. Abolbashari, M.H.; Freidoonimehr, N.; Nazari, F.; Rashidi, M.M. Entropy Analysis for an Unsteady MHD Flow past a Stretching Permeable Surface in Nanofluid. Powder Tech. 2014, 267, 256-267. [CrossRef]

21. Rashidi, M.M.; Hosseini, A.; Pop, I.; Kumar, S.; Freidoonimehr, N. Comparative numerical study of single and two-phase models of nanofluid heat transfer in wavy channel. Appl. Math. Mech. 2014, 35, 831-848. [CrossRef]

22. Rashidi, M.M.; Momoniat, E.; Ferdows, M.; Basiriparsa, A. Lie group solution for free convective flow of a nanofluid past a chemically reacting horizontal plate in a porous media. Math. Probl. Eng. 2014, 2014. [CrossRef]

23. Garoosi, F.; Rohani, B.; Rashidi, M.M. Two-Phase Mixture Modeling of Mixed Convection of Nanofluids in a Square Cavity with Internal and External Heating. Powder Tech. 2015, 275, 304-321. [CrossRef]

24. Garoosi, F.; Bagheri, G.; Rashidi, M.M. Two phase simulation of natural convection and mixed convection of the nanofluid in a square cavity. Powder Tech. 2015, 275, 239-256. [CrossRef]

25. Garoosi, F.; Jahanshaloo, L.; Rashidi, M.M.; Badakhsh, A.; Ali, M.A. Numerical Simulation of Natural Convection of the Nanofluid in Heat Exchangers using a Buongiorno Model. App. Math. Comput. 2015, 254, 183-203. [CrossRef]

26. Freidoonimehr, N.; Rashidi, M.M.; Mahmud, S. Unsteady MHD free convective flow past a permeable stretching vertical surface in a nanofluid. Int. J. Therm. Sci. 2015, 87, 136-145. [CrossRef]

27. Akbari, M.; Behzadmehr, A. Developing mixed convection of a nanofluid in a horizontal tube with uniform heat flux. Int. J. Numer. Meth. Heat Fluid Flow 2007, 17, 566-586. [CrossRef]

28. Akbari, M.; Behzadmehr, A.; Shahraki, F. Fully developed mixed convection in horizontal and inclined tubes with uniform heat flux using nanofluid. Int. Comm. Heat Fluid Flow 2008, 29, 545-556. [CrossRef]

29. Aminfar, H.; Mohammadpourfard, M.; AhangarZonouzi, S. Numerical study of the ferrofluid flow and heat transfer through a rectangular duct in the presence of a non-uniform transverse magnetic field. J. Magn. .Magn. Mater. 2013, 327, 31-42. [CrossRef]

30. Tzirtzilakis, E.E.; Kafoussias, N.G. Three-dimensional magnetic fluid boundary layer flow over a linearly stretching sheet. Int. Heat Transf. 2010, 132, 11701-11708. [CrossRef]

31. Manninen, M.; Taivassalo, V.; Kallio, S. On the Mixture Model for Multiphase Flow; VTT Publications: Espoo, Finland, 1996.

32. Oztop, H.F.; Abu-Nada, E. Numerical study of natural convection in partially heated rectangular enclosures filled with nanofluids. Int. J. Heat Fluid Flow 2008, 29, 1326-1336. [CrossRef]

33. Brinkman, H.C. The viscosity of concentrated suspensions and solutions. J. Chem. Phys. 1952, 20, 571-582. [CrossRef]

34. Chon, C.H.; Kihm, K.D.; Lee, S.P.; Choi, S.U.S. Empirical correlation finding the role of temperature and particle size for nanofluid $\left(\mathrm{Al}_{2} \mathrm{O}_{3}\right)$ thermal conductivity enhancement. Appl. Phys. Lett. 2005, 87, 1-3. [CrossRef]

35. Chai, L.; Xia, G.; Zhou, M.; Li, J. Numerical simulation of fluid flow and heat transfer in a microchannel heat sink with offset fan-shaped reentrant cavities in sidewall. Int. Commun. Heat Mass Transf. 2011, 38, 577-584. [CrossRef] 
36. Balaji, C.; Hölling, M.; Herwig, H. Entropy generation minimization in turbulent mixed convection flows. Int. Commun. Heat Mass Transf. 2007, 34, 544-552. [CrossRef]

37. Bejan, A. Entropy Generation through Heat and Fluid Flow; Wiley: New York, NY, USA, 1982. 